\title{
Pattern Analysis of Sorghum Genotype $\times$ Environment Interaction for Leaf, Panicle, and Grain Anthracnose in Mali
}

\author{
D. E. Hess, Principal Plant Pathologist, ICRISAT, B.P. 320, Bamako, Mali; R. Bandyopadhyay, Principal Plant \\ Pathologist, ICRISAT, Patancheru 502 324, Andhra Pradesh, India; and I. Sissoko, Scientific Officer, ICRISAT, \\ B.P. 320, Bamako, Mali
}

\begin{abstract}
Hess, D. E., Bandyopadhyay, R., and Sissoko, I. 2002. Pattern analysis of sorghum genotype $\times$ environment interaction for leaf, panicle, and grain anthracnose in Mali. Plant Dis. 86:13741382.

Resistance to anthracnose, caused by Colletotrichum graminicola, in sorghum was identified through field screening at two locations (Samanko and Longorola) in Mali. The occurrence and progress of anthracnose were monitored on 19 sorghum lines plus resistant and susceptible checks in the 1996 to 1998 rainy seasons. Foliar anthracnose severity was assessed at regular intervals throughout the season. Area under the disease progress curve (AUDPC) was calculated for each genotype. Anthracnose severity was also evaluated on the peduncle, rachis and glumes, panicle, and grain. For the characters under study, the site $\times$ year and site $\times$ year $\times$ line interactions accounted for the genotype $\times$ environment interactions. Pattern analysis was applied to the environment-standardized matrix of genotype $\times$ environment means to analyze these interactions and elucidate genotypic adaptation. None of the lines was completely (hypersensitive) resistant to the disease, but 12 showed high levels of stable resistance to both foliar and panicle anthracnose. Only one was moderately susceptible to both forms of the disease. In addition to identifying varieties that can be grown in zones to which they are adapted, additional genotypes were identified that can serve as sources of resistance in regional breeding programs.
\end{abstract}

Sorghum (Sorghum bicolor) is a basic staple food for the people of West Africa, accounting for $37 \%$ of total food grain production in the region (7). A broad range of plant pathogens limits the productivity of the crop in West Africa (25). Anthracnose, caused by Colletotrichum graminicola, is an important disease in the region and in many other parts of the world $(18,23,26)$. The fungus infects all aboveground portions of the plant (stalk, leaf, peduncle, panicle, and grain) and develops in both living and dead tissues (2,23). Disease symptoms include a foliar phase, stalk rot, and panicle and grain anthracnose. Physiological races within populations of C. graminicola have been suggested to occur in Niger (17), India (19), the United States (1), and Brazil (5). Symptoms can vary due to differences in pathogen virulence, host resistance, and/or changes in the physiological state

Corresponding author: D. E. Hess

E-mail: dhess@purdue.edu

Current address of D. E. Hess: Agronomy Department, Purdue University, W. Lafayette, IN 47907.

Current address of R. Bandyopadhyay: IITA, Oyo Road, Ibadan, Nigeria.

Accepted for publication 13 August 2002.

Publication no. D-2002-1021-01R

(c) 2002 The American Phytopathological Society of the host following infection. Multilocation studies of a variety of cultivars would enhance understanding of the in- fluence of environment on disease development and yield loss (26).

The most common and severe form of the disease is foliar anthracnose, which can reduce the grain and stover yield of susceptible cultivars by $50 \%$ or more $(3,11,12)$. Foliar anthracnose infection causes significant reduction in grain yield through reduced kernel weight and grain abortion (26). Host-plant resistance is the most economical approach for successful management of the disease. Availability of sources of resistance is a prerequisite for breeding adapted, resistant, high-yielding sorghum cultivars. Typically, screening of sorghum for reaction to anthracnose targets the foliar manifestation of the disease. However, during a survey conducted in southern Mali in November 1996, panicle anthracnose was frequently observed affecting the peduncle, rachis, glumes, and grains of local varieties in farmers' fields, indicating a need for resistance screening based on panicle reactions. Thus, the objectives of this study were to (i) evaluate

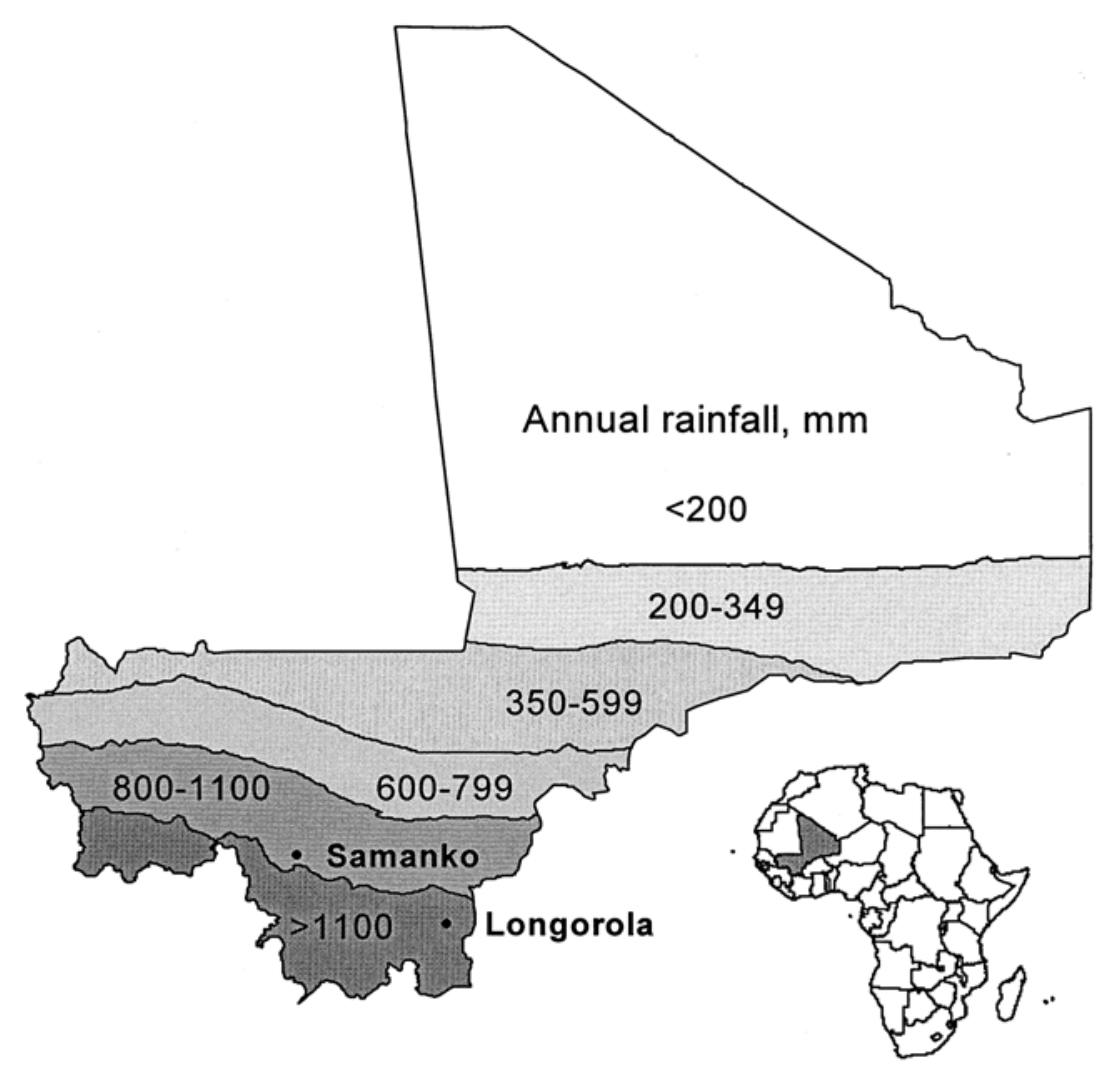

Fig. 1. Locations in Mali where the two sorghum anthracnose nurseries were evaluated. 
selected sorghum lines for reaction to foliar and panicle anthracnose, and (ii) identify sources of stable resistance to anthracnose, i.e., resistance that holds up in varying environments.

\section{MATERIALS AND METHODS}

Experiments were conducted as a randomized complete block design with two replications at two locations in Mali's Northern Guinea Zone (Fig. 1) during three (1996 to 1998) cropping seasons. One trial was sown at the International Crops Research Institute for the Semi-Arid Tropics (ICRISAT) station in Samanko $\left(12^{\circ} 32^{\prime} \mathrm{N}\right.$ latitude; $8^{\circ} 7^{\prime} \mathrm{W}$ longitude), $25 \mathrm{~km}$ southwest of Bamako. The second trial was at the Institut d'Economie Rurale (IER) station in Longorola ( $11^{\circ} 21^{\prime} \mathrm{N}$ latitude; $5^{\circ} 41^{\prime}$ W longitude), $8 \mathrm{~km}$ north of Sikasso.

Field trials. A basal application of a compound N-P-K fertilizer (15-15-15; 100 $\mathrm{kg} \mathrm{ha} \mathrm{h}^{-1}$ ) was applied at field preparation. Nineteen sorghum lines plus resistant and susceptible checks (Table 1) were evaluated in the field. These test entries were selected for their good levels of resistance to foliar anthracnose in field evaluation for the previous 3 years at both locations. The sorghum genotypes studied were of short (anthesis within 75 days after sowing [DAS]) and medium (anthesis between 76 and 90 DAS) cycles (Table 1). All have tan plant and white grain and belong to race caudatum, except for IS 14384 , a pigmented plant, red-seeded sorghum of race guinea, and IS 21629, a pigmented plant, straw-seeded sorghum of race guineacaudatum (10). IS 21658 and IS 18442 served as resistant and susceptible checks, respectively.

Natural disease pressure in the anthracnose nurseries was enhanced by using infestor rows consisting of a mixture of three to four anthracnose-susceptible sorghum genotypes. The infestor rows were sown adjacent to each two-row test plot. All plants in the infestor rows and test materials were inoculated by placing sorghum grains bearing mature acervuli of $C$. graminicola into the whorls of 30-day-old plants. The infected grains used for inoculation were harvested during the previous growing season and stored in the laboratory. Sowing dates at Samanko were 15 June 1996 and 24 June in both 1997 and 1998; at Longorola, seeds were sown on 20, 27, and 24 June in 1996, 1997, and 1998, respectively. Plots of each test entry and check consisted of two rows $4 \mathrm{~m}$ in length, spaced $0.75 \mathrm{~m}$ apart. Plant-to-plant spacing within row was $0.4 \mathrm{~m}$. Carbofuran (Furadan) was applied with sorghum seed (0.025 mg a.i. per sowing hole or "hill") to control insects (e.g., millipedes, ants, and termites). About 30 days after emergence and following a rainfall event, plots were thinned to two plants per hill (leaving a maximum of 20 plants per row). At Samanko, a top dressing of $50 \mathrm{~kg}$ of urea per ha $(46 \% \mathrm{~N})$ was applied at $45 \mathrm{DAS}$. At Longorola, urea was applied in two equal split applications at 30 and 45 DAS for a total of $46 \mathrm{~kg} \mathrm{~N} \mathrm{ha}^{-1}$. During the cropping season, fields were weeded three times. Days required after sowing for $50 \%$ of plants in a plot to flower was noted. Height of five plants from the ground to tip of panicles was also recorded.

Disease assessment. Plants were closely monitored to record the first appearance of anthracnose on leaves and panicles in each plot. A 1 to 9 scale was used to evaluate the extent of anthracnose damage on five plant organs: leaf surface, rachis, peduncle, panicle (including rachis, rachis branches, glumes, and grain), and grains (damage resulting in reduction in grain size or grain discoloration or grain abortion) (24). In this scale, $1=$ no disease, $2=1$ to $5 \%, 3=$

Table 1. Plant characteristics, pedigree, and agronomic traits of 21 sorghum lines evaluated for field reaction to Colletotrichum graminicola in Mali, 1996 to 1998 cropping seasons

\begin{tabular}{|c|c|c|c|c|c|c|c|c|}
\hline Genotype & $\begin{array}{l}\text { Entry } \\
\text { no. }\end{array}$ & Pedigree & Origin & Race $^{a}$ & Plant type & $\begin{array}{l}\text { Grain } \\
\text { color }\end{array}$ & $\begin{array}{l}\text { Days to } 50 \% \\
\text { anthesis }\end{array}$ & $\begin{array}{c}\text { Plant } \\
\text { height }(\mathrm{m})\end{array}$ \\
\hline ICSV 91020 & 1 & $\begin{array}{l}{[\mathrm{US} / \mathrm{R} \text { bulk } \times(\mathrm{CSV} 4} \\
\times \text { GPR 370)]-2-2-2-2 }\end{array}$ & ICRISAT & $\mathrm{C}$ & Tan & White & 77 & 2.8 \\
\hline CEM 328/1-1-1-2 & 2 & CIRAD $370 \times$ I 24 & CIRAD/ICRISAT & $\mathrm{C}$ & Tan & White & 75 & 2.8 \\
\hline CEM 326/11-5-1-1 & 3 & IS $9225 \times$ CIRAD 370 & CIRAD/ICRISAT & $\mathrm{C}$ & Tan & White & 73 & 2.8 \\
\hline CEM 328/2-1-1-3 & 4 & CIRAD $370 \times$ I 24 & CIRAD/ICRISAT & $\mathrm{C}$ & Tan & White & 76 & 3.0 \\
\hline CEM 328/3-3-1-1 & 5 & CIRAD $370 \times$ I 24 & CIRAD/ICRISAT & $\mathrm{C}$ & Tan & White & 79 & 2.9 \\
\hline CEM 330/1-1-2-1 & 6 & CIRAD $370 \times$ IS 8136 & CIRAD/ICRISAT & $\mathrm{C}$ & Tan & White & 82 & 2.4 \\
\hline CEM 342/6-4-1 & 7 & $\begin{array}{l}\text { SSV } 5 \times \text { F } 2(\text { SSV } 5 \\
\times \text { Kokologho })\end{array}$ & CIRAD/ICRISAT & $\mathrm{C}$ & Tan & White & 79 & 2.8 \\
\hline ICSB 38 & 8 & $\begin{array}{l}{[(\mathrm{BT} \times 623 \times \mathrm{MR} 862) \mathrm{B} \text { lines }} \\
\text { bulk }]-5-1-3-5\end{array}$ & ICRISAT & $\mathrm{C}$ & Tan & White & 71 & 1.6 \\
\hline ICSB 39 & 9 & $\begin{array}{l}{[(\mathrm{BT} \times 623 \times \mathrm{MR} 862) \mathrm{B} \text { lines }} \\
\text { bulk]-5-1-3-3 }\end{array}$ & ICRISAT & $\mathrm{C}$ & Tan & White & 71 & 1.5 \\
\hline ICSB 41 & 10 & $\begin{array}{l}{[(\mathrm{BT} \times 623 \times \mathrm{MR} 862) \mathrm{B} \text { lines }} \\
\text { bulk]-5-3-6-2 }\end{array}$ & ICRISAT & $\mathrm{C}$ & Tan & White & 72 & 1.6 \\
\hline ICSB 88019 & 11 & (IS $152 \times$ DJ 6514)-8-1-1-1-1 & ICRISAT & $\mathrm{C}$ & Tan & White & 60 & 1.7 \\
\hline ICSV 901 & 12 & (M60264 × Naga White) $1-2-5-2$ & ICRISAT & $\mathrm{C}$ & Tan & White & 74 & 2.1 \\
\hline ICSV 902 & 13 & (M60264 × Naga White) & ICRISAT & $\mathrm{C}$ & Tan & White & 74 & 2.5 \\
\hline IS 14384 & 14 & $\begin{array}{l}\text { Germ plasm accession from } \\
\text { Zimbabwe }\end{array}$ & Zimbabwe & $\mathrm{G}$ & Pigmented & Red & 68 & 3.3 \\
\hline IS 21629 & 15 & Malawi & ICRISAT & $\mathrm{G}-\mathrm{C}$ & Pigmented & Straw & 78 & 3.9 \\
\hline IS 2834 & 16 & $\begin{array}{l}\text { Germ plasm accession from } \\
\text { Zimbabwe }\end{array}$ & Zimbabwe & $\mathrm{C}$ & Tan & White & 66 & 2.9 \\
\hline IS 3555 & 17 & $\begin{array}{l}\text { Germ plasm accession from } \\
\text { the Sudan }\end{array}$ & Sudan & $\mathrm{C}$ & Tan & White & 74 & 3.7 \\
\hline IS 9738 & 18 & $\begin{array}{l}\text { Germ plasm accession from } \\
\text { the Sudan }\end{array}$ & Sudan & $\mathrm{C}$ & Tan & White & 75 & 3.3 \\
\hline Naga White & 19 & $\begin{array}{l}\text { Germ plasm accession from } \\
\text { Ghana }\end{array}$ & Ghana & $\mathrm{C}$ & Tan & White & 66 & 2.4 \\
\hline $\begin{array}{l}\text { IS } 21658 \\
\text { (resistant check) }\end{array}$ & 20 & $\begin{array}{l}\text { Germ plasm accession from } \\
\text { Malawi }\end{array}$ & Malawi & $\mathrm{C}$ & Tan & White & 76 & 3.8 \\
\hline $\begin{array}{l}\text { IS } 18442 \\
\text { (susceptible check) }\end{array}$ & 21 & $\begin{array}{l}\text { Germ plasm accession from } \\
\text { India }\end{array}$ & India & $\mathrm{C}$ & Tan & White & 65 & 2.9 \\
\hline $\mathrm{SE}( \pm)$ & & & & & & & 2.8 & 0.19 \\
\hline Mean & & & & & & & 73 & 2.7 \\
\hline $\mathrm{CV}(\%)$ & & & & & & & 4 & 7 \\
\hline
\end{tabular}

${ }^{\mathrm{a}} \mathrm{C}=$ Caudatum; $\mathrm{G}=$ Guinea. 
6 to $10 \%, 4=11$ to $20 \%, 5=21$ to $30 \%, 6$ $75 \%$, and $9=$ more than $75 \%$ of the plant organ affected by $C$. graminicola. Disease severity was recorded on 10 randomly tagged plants in each plot. Disease progress was followed on the leaves beginning at first disease appearance (4 to 6 weeks after sowing), with notes taken at 2-week intervals up to anthesis and at weekly intervals thereafter. The panicles of the tagged plants were harvested within 10 days after grain maturity (at about 120 DAS), sun-dried, and kept separate. Disease severity on the peduncle, rachis, and grain was evaluated separately. In addition, overall damage to the panicle (including the peduncle, rachis and glumes, and grain) was scored.

Data analysis. Before analysis, the disease severity rating of each plant was converted to percent severity using the interval midpoint (i.e., $1=0,2=2.5,3=7.5,4=$ $15,5=25,6=35,7=45,8=62.5$, and 9 $=87.5 \%)$. Foliar disease progress data were used to determine area under the disease progress curve (AUDPC) calculated according to Shaner and Finney (20). An analysis of variance was performed for this randomized complete block design, repeated in sites and years. Lines were considered fixed, and sites, years, and blocks were considered to be random effects. Expected mean squares were computed according to classical methods (22). Square root transformations were performed on foliar percent disease and AUDPC, with log transformations on panicle and grain percent disease in order to achieve homogeneity of error variances. In addition, the susceptible check IS 18442 and moderately susceptible CEM 342/6-4ance for the same reason. ANOVA was calculated using the SAS GLM procedure (SAS Institute, Cary, NC). Coefficients of phenotypic correlation among agronomic characters and disease severities (days to $=31$ to $40 \%, 7=41$ to $50 \%, 8=51$ to 1 were omitted from the analysis of vari-

anthesis [ANTH], plant height [HGT], the time of first appearance of anthracnose on the leaf [FOLA] and panicle [PANA], foliar anthracnose severity at 100 DAS [FOL], area under the disease progress curve [AUDPC], and anthracnose severity on the panicle [PAN], peduncle [PED], rachis [RAC], and grain [GRA]) were calculated for all 21 sorghum lines.

Testing of genotypes in diverse environments can result in substantial genotype $\times$ environment $(\mathrm{G} \times \mathrm{E})$ interactions. For these data, $\mathrm{G} \times \mathrm{E}$ interactions accounted for 56 to $72 \%$ of observed variation. Various analytic approaches are available to analyze these interactions and elucidate genotypic adaptation. Pattern analysis examines data structure through the combined use of classification and ordination techniques on a matrix of inter-individual differences $(4,9)$. Individuals may be genotypes or environments, depending on the relationships to be studied. The software package GEBEI (28) was used to apply appropriate clustering and ordination procedures for pattern analysis of the genotype $\times$ environment data. Procedures are discussed by Wishart (30), Kroonenberg (16), and DeLacy et al. (8).

The program analyzes two-way $\mathrm{G} \times \mathrm{E}$ data sets. Cluster analysis simplifies data sets by grouping individuals with similar responses for attributes of interest. Genotypes with similar response patterns for the chosen character are grouped over all environments, and environments with similar response patterns, in turn, are grouped over all genotypes $(4,9)$. The program uses an agglomerative hierarchical classification procedure (29) requiring a measure of association among individuals and a fusion strategy. The proximity measure assesses closeness in multidimensional space; the fusion strategy is the algorithm that determines if an individual or group should join another individual or group to form a new cluster (30). Squared Euclidean distance is used as the dissimilarity measure, and

Table 2. Effect of site, year, and sorghum line on anthracnose severity in screening trials carried out at Longorola and Samanko during 1996 to 1998 in Mali

\begin{tabular}{|c|c|c|c|c|c|}
\hline \multirow[b]{2}{*}{$\begin{array}{l}\text { Source } \\
\text { of variance }\end{array}$} & \multirow[b]{2}{*}{ df } & \multicolumn{4}{|c|}{ Trait mean squares } \\
\hline & & $\begin{array}{c}\text { Foliar } \\
\text { anthracnose }^{\mathrm{a}}\end{array}$ & $\mathbf{A U D P C}^{\mathbf{b}}$ & $\begin{array}{c}\text { Grain } \\
\text { anthracnose }\end{array}$ & $\begin{array}{c}\text { Panicle } \\
\text { anthracnose }^{c}\end{array}$ \\
\hline Site & 1 & $4.4398 \mathrm{~ns}$ & $42.7382 \mathrm{~ns}$ & $0.45077 \mathrm{~ns}$ & $1.4488 \mathrm{~ns}$ \\
\hline Year & 2 & $3.8659 \mathrm{~ns}$ & $6.3358 \mathrm{~ns}$ & $3.6225 \mathrm{~ns}$ & $2.0108 \mathrm{~ns}$ \\
\hline Site $\times$ year & 2 & $11.7534 * * \mathrm{~d}$ & $317.3861 * *$ & $5.6194 * *$ & $4.9100 * *$ \\
\hline Block (site × year) & 6 & $0.1194 \mathrm{~ns}$ & $4.7209 \mathrm{~ns}$ & $0.4855^{* *}$ & $0.3736 * *$ \\
\hline Line & 18 & $2.6037 *$ & $79.6191 * *$ & $0.3772 *$ & $0.4985^{*}$ \\
\hline Site $\times$ line & 18 & $1.0390 \mathrm{~ns}$ & $25.6192 \mathrm{~ns}$ & $0.1717 \mathrm{~ns}$ & $0.1833 \mathrm{~ns}$ \\
\hline $\begin{array}{l}\text { Pooled }[(\mathrm{Y} \times \mathrm{L}) \\
\quad+(\mathrm{S} \times \mathrm{Y} \times \mathrm{L})]\end{array}$ & 72 & $0.5324 * *$ & $11.3040 * *$ & $0.1565^{*}$ & $0.1256 \mathrm{~ns}$ \\
\hline Year $\times$ line & 36 & $0.4650 \mathrm{~ns}$ & $8.6827 \mathrm{~ns}$ & $0.1339 \mathrm{~ns}$ & $0.1160 \mathrm{~ns}$ \\
\hline Site $\times$ year $\times$ line & 36 & $0.5998 * *$ & $13.9253^{* * *}$ & $0.1792 * *$ & $0.1351 *$ \\
\hline Expected error & 108 & 0.2204 & 6.1986 & 0.0916 & 0.0902 \\
\hline
\end{tabular}

${ }^{a}$ Square root transformation of percent foliar disease severity scored at 100 days after sowing.

${ }^{\mathrm{b}}$ Square root transformation of area under the disease progress curve.

${ }^{\mathrm{c}}$ Logarithmic transformation of percent disease severity scored at harvest (120 days after sowing).

$\mathrm{d} *$, ** Asterisks indicate level of significance such that * indicates $P \leq 0.05$ and $* *$ indicates $P \leq$ 0.01 . incremental sums of squares, Ward's method (27), is the fusion strategy. Oneway classification of the entries was chosen in order to keep the six test locations separate. The number of entry groups was defined considering the percentage of the sums of squares retained in the reduced $\mathrm{G}$ $\times \mathrm{E}$ matrix. The entry groups were defined based on a minimum percentage $(50 \%)$ of the sums of squares retained in the reduced entry $x$ environment matrix. Performance plots of different entry groups were used to characterize adaptation patterns. Biplots served to assess relations among entries, among environments, and between entries and environments (15). Entries close to the origin possess an average performance across all environments, and entries close to each other have similar performance. Small angles between two environment vectors indicate strong positive associations (similarity) between the two environments; $90^{\circ}$ angles indicate no association; and angles greater than $90^{\circ}$ represent dissimilarity. With regard to foliar anthracnose, entries distributed in the increasing direction of an environment vector show above-average disease severity in that environment, while those distributed in the opposite direction have less disease (are more resistant). To characterize entries, a line is drawn perpendicularly from a particular entry to an environment vector. The point of intersection indicates the entry's relative performance in that environment, i.e., for the same environment vector, a better genotype projects an intersection point that is farther along in the positive direction of the environment vector. As for ANOVA, the susceptible check IS 18442 and moderately susceptible CEM 342/6-41 were omitted from the analyses.

\section{RESULTS}

Conditions for sorghum growth and disease development were favorable at both locations during the 3 years of the trial. Total rainfall during the growing season (June through October) at Samanko was $723.9 \mathrm{~mm}$ over 49 days in 1996, $732.1 \mathrm{~mm}$ over 49 days in 1997, and 1,013.6 mm over 66 days in 1998. For the same respective years, rainfall at Longorola was $872.5 \mathrm{~mm}$ over 55 days, 904.2 over 61 days, and $1,011.5 \mathrm{~mm}$ over 75 days. Longorola is a wetter location (10-year average $=953$ $\mathrm{mm}$ ) than Samanko (10-year average $=814$ $\mathrm{mm})$; an exceptional rainfall year in Samanko (1998) is similar to an average year in Longorola (1998). Rainfall at Longorola in 1997 was above average throughout the cropping season. Average maximum and minimum temperatures during the cropping season in the 3 years were $22.1^{\circ} \mathrm{C}$ and $33.2^{\circ} \mathrm{C}$ in Samanko and $22.0^{\circ} \mathrm{C}$ and $31.5^{\circ} \mathrm{C}$ in Longorola.

Anthracnose appeared early (ca. 32 DAS) on the susceptible check IS 18442, and disease scores were very high: 9 for foliar, 8 for peduncle, and 9 for rachis an- 
thracnose. Anthracnose appeared on the panicle within 5 days after anthesis and became very severe ( 9 on the panicle, 8 on the grains). The disease appeared late (about 97 DAS and 21 days after anthesis) on the resistant check IS 21658. The resistant check was highly resistant to leaf, peduncle, and rachis anthracnose (scores predominantly 1) and only slightly less resistant to panicle and grain anthracnose (scores of 3 to 4 ).

Analysis of variance. Results of ANOVA for percent foliar anthracnose (100 DAS), AUDPC, grain and panicle anthracnose percent (120 DAS) are presented in Table 2. Genotype and $\mathrm{G} \times \mathrm{E}$ both significantly influenced disease development on leaf, grain, and panicle. Treatment means are presented in Table 3. For percent foliar anthracnose and AUDPC, the most resistant entries were nos. 11, 12, and 13 (ICSB 88019, ICSV 901, and ICSV 902, respectively). The most resistant entry to grain anthracnose was entry 14 , IS 14384, a red-seeded sorghum.

Percent foliar anthracnose was affected by a significant $(P \leq 0.01)$ genotype $\times$ site $x$ year interaction. The most resistant varieties (ICSB 88019, ICSV 901, ICSV 902, IS 2834, IS 9738, and Naga White) manifested resistance to foliar anthracnose at both locations in all 3 years. However, at Longorola, foliar disease levels were higher in 1997 (than in either 1996 or 1998) on several varieties that otherwise showed good levels of resistance (e.g., CEM 326/11-5-1-1, CEM 328/2-1-1-3, CEM 328/3-3-1-1, ICSB 38, and ICSB 39). In general, disease severity was greater on entries in the screening nursery at Samanko; but ICSB 41 showed consistently more foliar anthracnose in Longorola. AUDPC-based results followed the same trend as the single foliar observation at 100 DAS.

Panicle anthracnose gave a significant $(P \leq 0.05)$ genotype $\times$ site $\times$ year interaction. Disease severities on the panicle tended to exceed grain anthracnose severities but showed the same trends. Although anthracnose did occur on the peduncle and rachis of test sorghums, severity was low for both forms (score of $\leq 3$ ). In contrast, the susceptible check was heavily attacked (scores reaching 9 on both organs), and moderately susceptible CEM 342/6-4-1 had a score of 5 for rachis anthracnose.

With respect to grain anthracnose severity, the three-way (genotype $\times$ site $\times$ year) interaction was highly significant $(P \leq$ 0.01). The best entries, ICSB 88019, IS 14384, and IS 2834, exhibited less than 5\% average severity, although disease severities were higher at Longorola in 1996 and Samanko in 1998 (reaching 12 to $13 \%$ ). Eight other entries showed overall average disease severities of less than 10. ICSB 88019 was highly resistant to both foliar and grain anthracnose.

Correlations. In the materials under test, early anthesis and short stature were significantly correlated with early appearance of anthracnose on panicles (Table 4). Early appearance of foliar and panicle anthracnose were correlated with high levels of disease on all plant organs. Elevated levels of disease on the different panicle parts (peduncle, rachis, grain) were significantly correlated among themselves. In addition, severity of peduncle, rachis, panicle, and grain anthracnose were significantly correlated with AUDPC.

Pattern analysis. The dendrograms of the six environments showed differences for foliar anthracnose and AUDPC (Fig. 2). For foliar anthracnose, the Samanko and Longorola sites were clearly separated from each other. For AUDPC, 1996, a year with subnormal rainfall at Longorola, grouped with the Samanko environments. In the case of grain anthracnose, 1998, an above-average rainfall year in Samanko, grouped with the Longorola environments. For panicle anthracnose, Longorola 1997 grouped with the Samanko environments.

The dendrograms of the 19 sorghum lines (18 entries plus resistant check) permitted identification of three entry groups for each of the four characters under study (Fig. 3). These were stable resistant group 1 and groups 2 and 3 made up of lines with variable resistance reaction across environments. For foliar anthracnose severity at 100 DAS, group $1(=\mathrm{F} 1)$ consisted of three lines: ICSB 88019, ICSV 901, and ICSV 902 (Fig. 3). In the case of AUDPC, an additional five lines grouped with ICSB

Table 3. Anthracnose severity on 21 sorghum lines screened at Longorola and Samanko, Mali, during the 1996 through 1998 cropping seasons

\begin{tabular}{|c|c|c|c|c|c|c|c|c|}
\hline \multirow[b]{2}{*}{ Entry $^{c}$} & \multicolumn{2}{|c|}{ Foliar anthracnose $^{\mathbf{a}}$} & \multicolumn{2}{|c|}{ AUDPC $^{\mathbf{b}}$} & \multicolumn{2}{|c|}{ Panicle anthracnose $^{a}$} & \multicolumn{2}{|c|}{ Grain anthracnose $^{\mathrm{a}}$} \\
\hline & Square root & $\begin{array}{c}\text { Back- } \\
\text { transformed }\end{array}$ & Square root & $\begin{array}{c}\text { Back- } \\
\text { transformed }\end{array}$ & $\log _{10}$ & $\begin{array}{c}\text { Back- } \\
\text { transformed }\end{array}$ & $\log _{10}$ & $\begin{array}{c}\text { Back- } \\
\text { transformed }\end{array}$ \\
\hline 1 & 1.00 & 0.99 & 4.41 & 19.42 & 1.16 & 14.31 & 1.08 & 12.03 \\
\hline 2 & 1.19 & 1.42 & 5.08 & 25.84 & 0.89 & 7.78 & 0.81 & 6.46 \\
\hline 3 & 1.34 & 1.79 & 6.59 & 43.46 & 1.24 & 17.31 & 1.00 & 9.93 \\
\hline 4 & 1.08 & 1.16 & 4.87 & 23.73 & 1.19 & 15.36 & 1.09 & 12.17 \\
\hline 5 & 1.37 & 1.86 & 8.00 & 63.94 & 1.10 & 12.57 & 1.05 & 11.24 \\
\hline 6 & 1.28 & 1.63 & 7.39 & 54.55 & 0.95 & 8.84 & 0.80 & 6.25 \\
\hline 8 & 1.22 & 1.50 & 5.77 & 33.29 & 1.27 & 18.41 & 1.17 & 14.85 \\
\hline 9 & 1.32 & 1.74 & 6.15 & 37.78 & 1.11 & 12.79 & 1.02 & 10.44 \\
\hline 10 & 1.63 & 2.66 & 7.64 & 58.30 & 1.23 & 16.98 & 1.17 & 14.62 \\
\hline 11 & 0.06 & 0.00 & 0.30 & 0.09 & 0.82 & 6.62 & 0.56 & 3.59 \\
\hline 12 & 0.30 & 0.09 & 0.98 & 0.97 & 0.90 & 7.93 & 0.74 & 5.55 \\
\hline 13 & 0.17 & 0.03 & 0.77 & 0.59 & 0.86 & 7.22 & 0.75 & 5.56 \\
\hline 14 & 1.74 & 3.02 & 9.82 & 96.40 & 0.61 & 4.03 & 0.44 & 2.72 \\
\hline 15 & 0.89 & 0.80 & 4.76 & 22.66 & 1.01 & 10.16 & 0.99 & 9.71 \\
\hline 16 & 0.79 & 0.63 & 4.14 & 17.12 & 0.77 & 5.85 & 0.66 & 4.57 \\
\hline 17 & 1.16 & 1.33 & 7.24 & 52.35 & 1.14 & 13.65 & 0.96 & 9.11 \\
\hline 18 & 0.84 & 0.70 & 3.34 & 11.18 & 1.07 & 11.82 & 1.00 & 9.92 \\
\hline 19 & 0.48 & 0.23 & 2.78 & 7.74 & 1.03 & 10.62 & 0.84 & 6.98 \\
\hline 20 & 0.90 & 0.81 & 4.56 & 20.75 & 1.02 & 10.37 & 0.98 & 9.62 \\
\hline LSD $^{d}$ & \multicolumn{2}{|c|}{0.69} & \multicolumn{2}{|c|}{3.29} & \multicolumn{2}{|c|}{0.33} & \multicolumn{2}{|c|}{0.31} \\
\hline 7 & 3.22 & 10.37 & 18.77 & 352.15 & 1.58 & 37.72 & 1.48 & 30.20 \\
\hline 21 & 7.66 & 58.61 & 41.92 & $1,757.56$ & 1.71 & 51.66 & 1.71 & 51.66 \\
\hline LSD $^{\mathrm{e}}$ & \multicolumn{2}{|c|}{0.49} & \multicolumn{2}{|c|}{2.33} & \multicolumn{2}{|c|}{0.23} & \multicolumn{2}{|c|}{0.22} \\
\hline
\end{tabular}

a Disease levels were assessed on foliage at 100 days after sowing and on the panicle and grain at 120 days after sowing; ratings were based on $1=$ no disease to $9=$ more than $75 \%$ disease severity.

b AUDPC is area under the disease progress curve and is a measure of disease over the growing season.

${ }^{\mathrm{c}}$ For entry names see Table 1.

${ }^{\mathrm{d}} \operatorname{LSD}(P \leq 0.05)$ for comparison of entry 1 to 6 and 8 to 20 means.

${ }^{\mathrm{e}} \operatorname{LSD}(P \leq 0.05)$ for comparison of entry 7 and 21 (excluded from ANOVA) means to other test entries. 
88019, ICSV 901, and ICSV 902 in resistance group 1 (=A1). These are: ICSV 91020, CEM 328/1-1-1-2, CEM 328/2-1-13, IS 9738, and Naga White. When grain anthracnose was considered, 10 entries exhibited stable resistance in group 1 (=G1). Notably, entries ICSB 88019, ICSV
901, and ICSV 902, also resistant to foliar anthracnose, were among them. In the case of panicle anthracnose, eight entries grouped resistant (P1). These comprised seven entries that exhibited stable resistance to grain anthracnose and the resistant check, IS 21658.
Performance plots of the individual entry groups showed the patterns of genotype adaptation to the test environments (Fig. 4). For foliar anthracnose severity and AUDPC, entries ICSB 88019, ICSV 901, and ICSV 902 in group 1 showed superior, stable resistance in all test envi-

Table 4. Pearson correlation coefficients $(r)$ among agronomic characters and anthracnose severities of 21 sorghum lines in Mali in 1996 through $1998^{\text {a }}$

\begin{tabular}{|c|c|c|c|c|c|c|c|c|c|}
\hline & ANTH & HGT & FOLA & PANA & FOL & AUDPC & PAN & PED & RAC \\
\hline HGT & 0.34 & $\ldots$ & $\ldots$ & $\ldots$ & $\ldots$ & $\ldots$ & $\ldots$ & $\ldots$ & $\ldots$ \\
\hline FOLA & -0.15 & -0.20 & $\ldots$ & $\ldots$ & $\ldots$ & $\ldots$ & $\ldots$ & $\ldots$ & $\ldots$ \\
\hline PANA & $0.63 * * \mathrm{~b}$ & $0.62 * *$ & 0.11 & & $\ldots$ & $\ldots$ & $\ldots$ & $\ldots$ & $\ldots$ \\
\hline FOL & -0.20 & 0.01 & $-0.70 * *$ & $-0.57 * *$ & $\ldots$ & $\ldots$ & $\ldots$ & $\ldots$ & $\ldots$ \\
\hline AUDPC & -0.19 & 0.03 & $-0.71 * *$ & -0.56 ** & $1.00 * *$ & $\ldots$ & $\ldots$ & $\ldots$ & $\ldots$ \\
\hline PAN & -0.04 & -0.19 & $-0.69 * *$ & $-0.63 * *$ & $0.82 * *$ & $0.82 * *$ & $\ldots$ & $\ldots$ & $\ldots$ \\
\hline PED & -0.23 & 0.05 & $-0.67 * *$ & $-0.55 * *$ & $0.99 * *$ & $0.98 * *$ & $0.77 * *$ & $\ldots$ & $\ldots$ \\
\hline RAC & -0.13 & 0.00 & $-0.72 * *$ & $-0.56^{* *}$ & $0.97 * *$ & $0.98 * *$ & $0.89 * *$ & $0.96 * *$ & $\ldots$ \\
\hline GRA & 0.01 & -0.10 & $-0.75 * *$ & -0.56 ** & $0.86 * *$ & $0.86^{* * *}$ & $0.98 * *$ & $0.81 * *$ & $0.91 * *$ \\
\hline
\end{tabular}

${ }^{a}$ ANTH = days to anthesis; HGT = plant height; FOLA = appearance of anthracnose on the leaf; PANA = appearance of anthracnose on the panicle; FOL $=$ anthracnose severity $(\%)$ on the leaf at 100 days after sowing; AUDPC $=$ area under the disease progress curve; PAN $=$ anthracnose severity $(\%)$ on the panicle; $\mathrm{PED}=$ anthracnose severity $(\%)$ on the peduncle; RAC $=$ anthracnose severity $(\%)$ on the rachis; GRA $=$ anthracnose severity $(\%)$ on the grain.

b $* *$ indicates correlations statistically significant at $P \leq 0.01$.

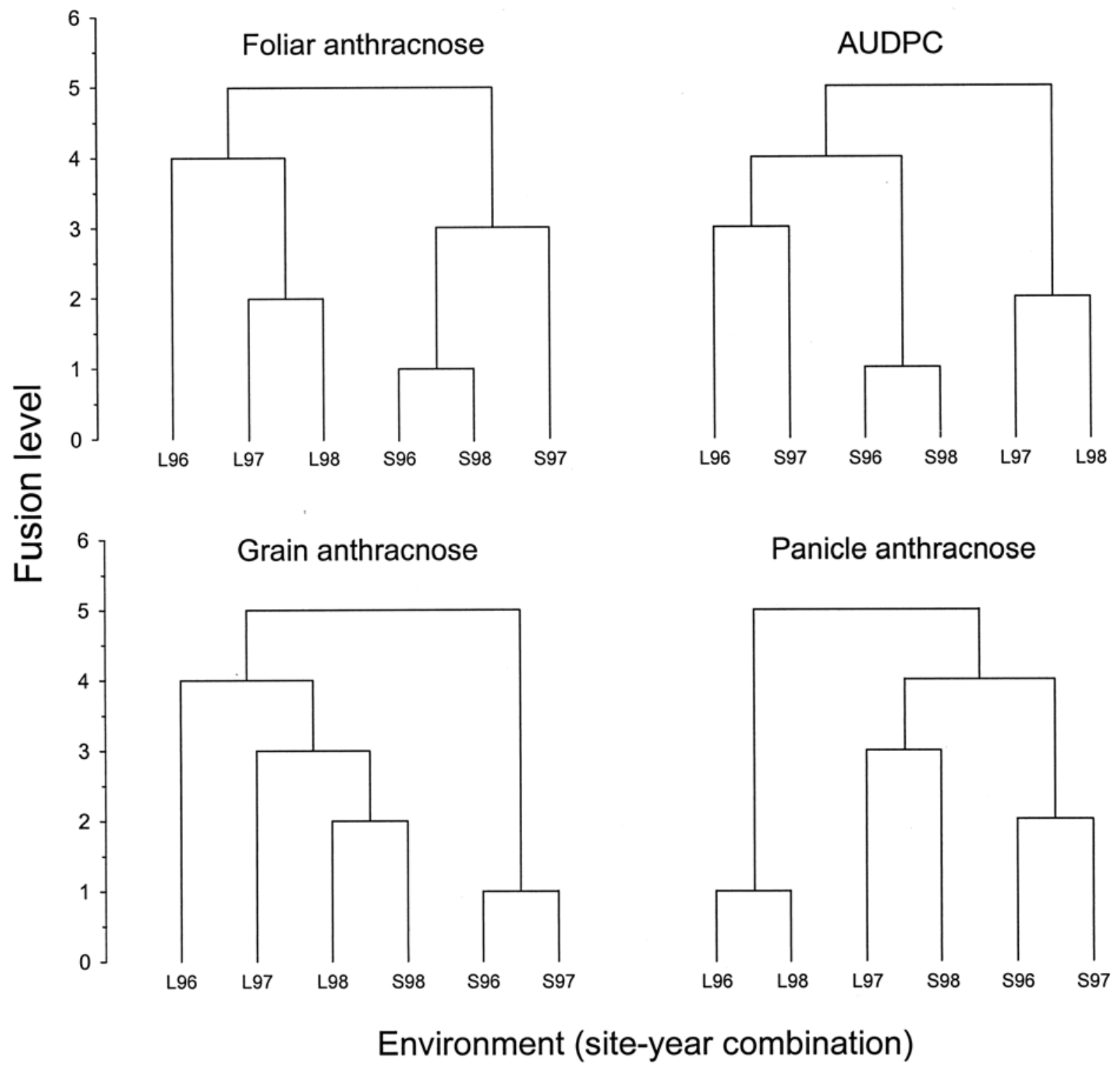

Fig. 2. Dendrograms of the six environments for foliar anthracnose percent severity (100 days after sowing), AUDPC (area under the disease progress curve), and grain and panicle anthracnose percent severity. $\mathrm{L}=$ Longorola; $\mathrm{S}=$ Samanko; $96=1996 ; 97=1997 ; 98=1998$. 
ronments. Groups 2 and 3 contributed most to the $\mathrm{G} \times \mathrm{E}$ interaction. Whereas ICSB 38, 39, and 41 showed aboveaverage resistance in Samanko, entries such as IS 21629 and IS 2834 performed better in Longorola. With regards to panicle and grain anthracnose, once again the most stable and resistant entries were ICSB 88019, ICSV 901, and ICSV 902, with group 2 and 3 members giving rise to significant $\mathrm{G} \times \mathrm{E}$.

In large tables with interaction, it is useful to present results in a form that analyzes the two-way interaction so that their relevance can be evaluated. Biplots that show both genotypes and environments simultaneously can be of great assistance in this respect. The results of the ordination analysis for sorghum anthracnose and their determinants (six environments) are presented in biplots of the first and second principal components for each trait (Fig. 5). The first two components accounted for $68,72,63$, and $58 \%$ of the total sums of squares of the line $\times$ environment interaction for percent foliar anthracnose, AUDPC, percent grain anthracnose, and percent panicle anthracnose, respectively. For all traits, the genotypic variation in some environments was less well represented than in others. The poorer representation is present in trials with shorter vectors extending from the origin. Similar genotypes have a small angle between them (the angle formed between the first point, the origin, and the second point), while dissimilar genotypes have a large angle. In a like manner, similar and dissimilar environments are separated by small and large angles, respectively. For percent foliar anthracnose and AUDPC, the 3 years within each site were observed to be similar, although differences appeared (i.e., angles between vectors approaching $90^{\circ}$ ) between specific Longorola and Samanko environments: L97 and S96 \& S98; L98 and S96 \& S98. A dry year in Longorola, 1996, was more similar to the Samanko environments than the years 1997 and 1998. This is another representation of the relationship shown in the Figure 2 dendrograms. However, for grain and panicle anthracnose, a wetter year in Longorola (1997) was similar to a wet year in Samanko (1998), with greatest dissimilarity existing between S96 or S97, and L96 and L98 (see also Fig. 2).

ICSV 901 and ICSV 902, entries 12 and 13 , both derived from a cross between M60264 and Naga White, grouped in all four biplots. Unrelated ICSB 88019 (entry 11) was found to perform as well for foliar anthracnose and AUDPC (see also Table 3). A similar association, although less tight, was observed among three B-lines: ICSB 38, 39, and 41, entries 8, 9, and 10, all progenies of a single plant derived from the cross [BTX $623(($ SC 108-3 $\times$ GPR 148)-18-4-1)) $\times$ B lines bulk]-5. The relat- edness of the two CEM lines, CEM 328/21-1-3 and CEM 328/3-3-1-1, entries 4 and 5 , issued from the cross CIRAD $370 \times \mathrm{I}$ 24 , was also in evidence. A number of test entries showed disease resistance superior to the resistant check. In the biplots they appear to the right of IS 21658 .

\section{DISCUSSION}

C. graminicola is able to infect and develop on all aboveground organs of the sorghum host. This was in evidence on the susceptible check IS 18442, where disease scores ranged from $7.5(45 \%)$ on the grains to $9(75$ to $100 \%)$ on the rachis and pani-

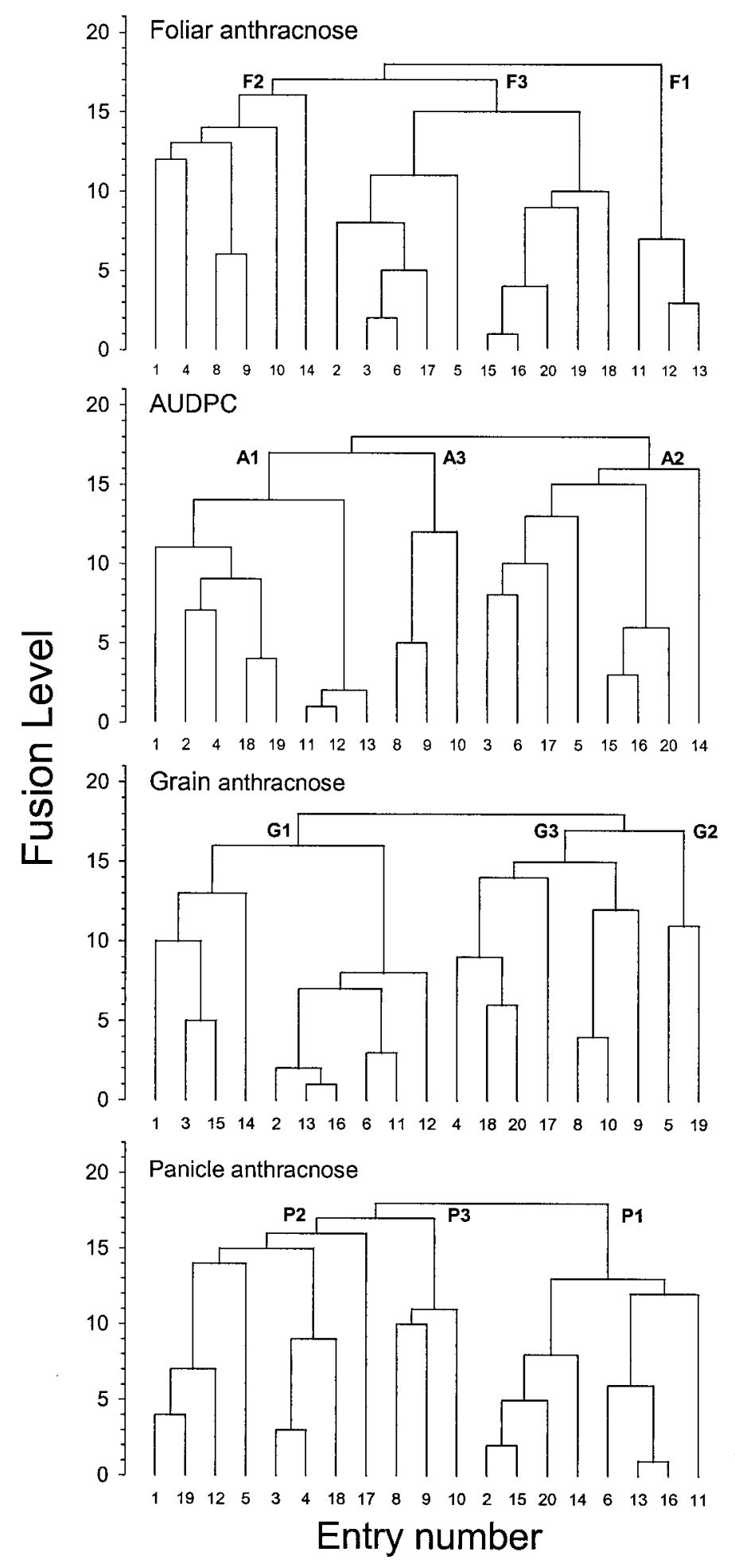

Fig. 3. Dendrograms showing hierarchical classification of 19 sorghum lines for foliar anthracnose score (100 days after sowing [DAS]), AUDPC (area under the disease progress curve), and grain and panicle anthracnose score 120 DAS). Resistant check = entry 20. Entry groups 1 to 3 represented by F1 to F3 for foliar anthracnose score (100 DAS), A1 to A3 for AUDPC, G1 to G4 for grain, and P1 to P4 for panicle anthracnose score (120 DAS). 


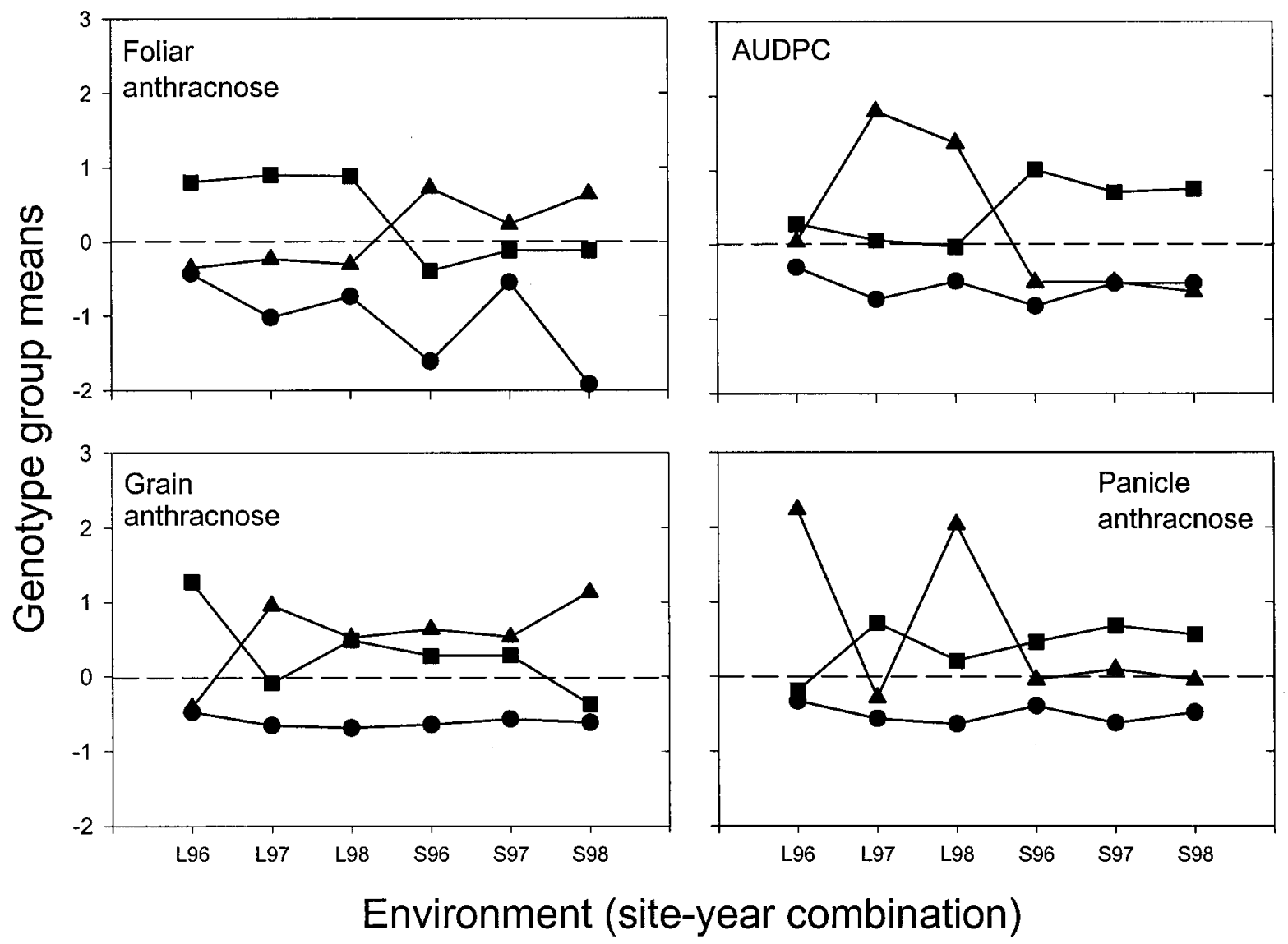

Fig. 4. Performance plots illustrating group performance of 19 sorghum lines in six Malian environments. $\mathrm{L}=$ Longorola; $\mathrm{S}=\mathrm{Samanko} ; 96=1996 ; 97=$ 1997; 98 = 1998; $\bullet$ = group $1 ; \boldsymbol{\nabla}=$ group $2 ; \boldsymbol{\Lambda}=$ group 3 .

cle. Nonetheless, all test genotypes, with the exception of CEM 342/6-4-1, were resistant $(<10 \%$ disease) to anthracnose on the rachis and peduncle (14). This is attributable to their having been selected for field resistance to foliar anthracnose prior to incorporation into this trial.

Anthracnose appeared earlier on the panicles of shorter-cycle genotypes (Table 3 ). We observed that as disease progressed up the plant, lower leaves developed severe infections and died while the fungus established itself and spread on upper plant parts. This vertical disease progression is reflected in the data in Table 3, where significant correlations exist between severity of disease on the grain, rachis, panicle, and leaves (AUDPC).

AUDPC is a useful measure that takes into account both duration and severity of disease. Nine evaluations of foliar anthracnose were made during the cropping season. Resistant ( $<5 \%$ disease) genotypes had AUDPCs of $\leq 100$, a moderately susceptible line had AUDPC of $<400$, and the susceptible check had AUDPC exceeding 1,000 . However, in this trial, the same conclusions could be drawn from a single foliar disease observation at 100 DAS, resulting in an important economy in time. Additionally, when working with genotypes of broadly diverse maturity, it would be advisable to do foliar disease evaluation at a common growth stage rather than at a common date post-sowing. Disease evaluation on the panicle and its constituent parts was effectively made at physiological maturity. The techniques developed and used in this study can serve pathologists and breeders in the region who wish to screen sorghum for reaction to foliar, grain, and panicle anthracnose.

Rainfall quantity and distribution are highly variable in Mali (21). The anthracnose screening nursery is an effective tool for screening activities at ICRISAT's center in Samanko. An increase in anthracnose severity in 1998 over 1997 was apparent (14), attributable in part to increasing disease pressure (inoculum in the soil) in the plot and in part to the elevated rainfall received in 1998. At Longorola, however, no permanent anthracnose nursery was available. As a result, the location of the screening trial changed from year to year following the cotton-maize-sorghum rotation practiced in the zone. This, coupled with below-average rainfall in 1998, resulted in reduced panicle and grain anthracnose severity in that year. Nonetheless, the use of infestor rows contributed to the success of screening activities in all six environments.

In the presence of significant $\mathrm{G} \times \mathrm{E}$, effectiveness of selection in a single environment is limited. Therefore, it is neces- sary to evaluate materials of interest over a range of environments. The study of $\mathrm{G} \times \mathrm{E}$ patterns can assist crop scientists in identifying regions of adaptation and develop more efficient testing procedures. Haussmann et al. (13) employed pattern analysis to identify sources of resistance in sorghum to the parasite striga for use in breeding programs. That work provided additional information on possible genetic variation in populations of the parasitic weed. We applied pattern analysis to identify sorghum varieties with excellent levels of resistance to both foliar and panicle anthracnose that can be grown in zones to which they are well adapted (i.e., ICSV 91020, CEM 328/1-1-1-2, ICSV 901, ICSV 902, and IS 9738). In addition, genotypes were identified that can serve as sources of resistance in breeding programs, including: ICSB 88019, ICSB 38, ICSB 39, and ICSB 41.

The two sites, Samanko and Longorola, may provide useful locations to investigate the effect, if any, of preseason (January to May) rainfall on availability of $C$. graminicola inoculum. At Samanko for the respective years 1996, 1997, and 1998, 189,129 , and $110 \mathrm{~mm}$ of rainfall were received in 8,15 , and 10 rainfall events. At Longorola, 114, 369, and $145 \mathrm{~mm}$ fell in 9, 14, and 10 rainfall events, respectively, in the same 3 years. In a wetter zone, it is 

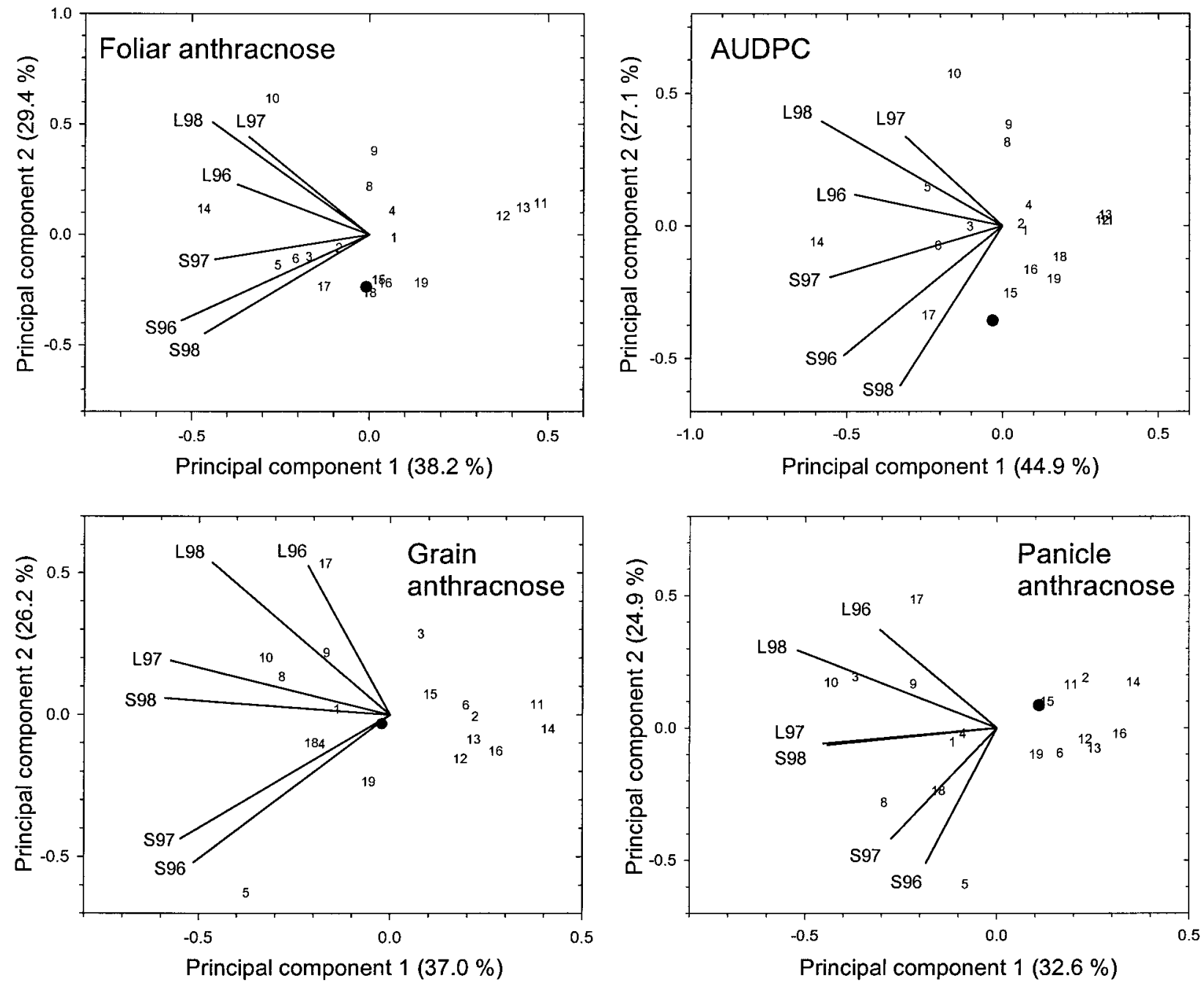

Fig. 5. Biplots of the first and second principal components for foliar anthracnose percent severity (100 days after sowing), AUDPC (area under the disease progress curve), and grain and panicle anthracnose percent severity (at harvest). Genotypes are represented by points, and environments are represented by vectors. Test entries are represented by numbers (clarified in Table 1) and the resistant check by a closed circle symbol.

possible that soil microflora may affect the viability of $C$. graminicola in plant debris at and below the soil surface, influencing the availability of inoculum in the following growing season (6). This question merits future investigation.

\section{ACKNOWLEDGMENTS}

We thank B. Diallo, O. Djiré, and the late A. Koné for capable technical assistance. We are grateful to J. Santini for statistical consultation.

\section{LITERATURE CITED}

1. Ali, M. E. K., and Warren, H. L. 1987. Physiological races of Colletotrichum graminicola on sorghum. Plant Dis. 71:402404.

2. Ali, M. E. K., and Warren, H. L. 1992. Anthracnose of sorghum. Pages 203-208 in: Sorghum and Millets Diseases: A Second World Review. W. A. J. de Milliano, R. A. Frederiksen, and G. D. Bengston, eds. International Crops Research Institute for the Semi-Arid Tropics, Patancheru 502 324, A. P., India.

3. Ali, M. E. K., Warren, H. L., and Latin, R. X. 1987. Relationship between anthracnose leaf blight and losses in grain yield of sorghum. Plant Dis. 71:803-806.

4. Byth, D. E., Eisemann, R. L., and DeLacy, I. H. 1976. Two-way pattern analysis of a large data set to evaluate genotypic adaptation. Heredity $37: 215-230$

5. Casela, C. R., Ferreira, A. S., Zeller, K. A., and Levy, M. 1995. Pathotype variation in the sorghum anthracnose fungus: A phylogenetic perspective for resistance breeding. Pages 257-276 in: Disease Analysis Through Genetics and Biotechnology: Interdisciplinary Bridges to Improved Sorghum and Millet Crops. J. F. Leslie and R. A. Frederiksen, eds. Iowa State University, Ames.

6. Casela, C. R., and Frederiksen, R. A. 1993. Survival of Colletotrichum graminicola sclerotia in sorghum stalk residues. Plant Dis. 77:825-827.

7. Debrah, S. K. 1993. Sorghum in Western Africa. Pages 19-37 in: Sorghum and Millets Commodity and Research Environments. D. E. Byth, ed. International Crops Research Institute for the Semi-Arid Tropics, Patancheru 502324 , A. P., India.

8. DeLacey, I. H., Basford, K. E., Cooper, M., Bull, J. K., and McLaren, C. G. 1996. Analysis of multi-environment trials - An historical perspective. Pages 39-124 in: Plant Adaptation and Crop Improvement. M. Cooper and G. L. Hammer, eds. CAB International, Wallingford, UK.

9. Fox, P. N., and Rosielle, A. A. 1982. Reducing the influence of environmental main effects on pattern analysis of plant breeding en- vironments. Euphytica 31:645-656

10. Harlan, J. R., and de Wet, J. M. J. 1972. A simplified classification of cultivated sorghum. Crop Sci. 12:172-176.

11. Harris, H. B., Johnson, B. J., Dobson, J. W., Jr., and Luttrell, E. S. 1964. Evaluation of anthracnose on grain sorghum. Crop Sci. 4:460462.

12. Harris, H. B., and Sowell, G., Jr. 1970. Incidence of Colletotrichum graminicola on Sorghum bicolor introductions. Plant Dis. Rep. 54:60-62.

13. Haussmann, B. I. G., Hess, D. E., Reddy, B. V. S., Mukuru, S. Z., Kayentao, M., Welz, H. G., and Geiger, H. H. 2001. Pattern analysis of genotype $x$ environment interaction for striga resistance and grain yield in African sorghum trials. Euphytica 122:297-308.

14. Hess, D. E., Bandyopadhyay, R., and Sissoko, I. 2001. Reactions of sorghum genotypes to leaf, panicle and grain anthracnose (Colletotrichum graminicola) under field conditions in Mali. Pages 163-177 in: Towards sustainable sorghum production, utilization, and commercialization in West and Central Africa: Proceedings of a Technical Workshop of the West and Central Africa Sorghum Research Network. 19-22 April 1999. Akintayo and J. Sedgo, eds. WCASRN/ICRISAT, Bamako, Mali.

15. Kempton, R. A. 1984. The use of biplots in 
interpreting variety by environment interactions. J. Agric. Sci. 103:123-135.

16. Kroonenberg, P. M. 1995. Introduction to Biplots for $G \times E$ Tables. Research Report \#51, Centre for Statistics, University of Queensland, Queensland, Australia. Published on-line.

17. Marley, P. S., Thakur, R. P., and Ajayi, O. 2001. Variation among foliar isolates of $\mathrm{Col}$ letotrichum sublineolum of sorghum in Nigeria. Field Crops Res. 69:133-142.

18. Néya, A., and Le Normand, M. 1998. Responses of sorghum genotypes to leaf anthracnose (Colletotrichum graminicola) under field conditions in Burkina Faso. Crop Prot. 17:47-53.

19. Pande, S., Mughogho, L. K., Bandyopadhyay, R., and Karunakar, R. I. 1991. Variation in pathogenicity and cultural characteristics of sorghum isolates of Colletotrichum graminicola in India. Plant Dis. 75:778-783.

20. Shaner, G., and Finney, R. E. 1977. The effect of nitrogen fertilization on the expression of slow mildewing resistance in Knox wheat. Phytopathology 67:1051-1056.

21. Sivakumar, M. V. K., Konaté, M., and Vir- mani, S. M. 1984 Agroclimatology of West Africa: Mali. Inform. Bull. no. 19. International Crops Research Institute for the SemiArid Tropics, Patancheru 502 324, A. P., India.

22. Steel, R. G. D., Torrie, J. H., and Dickey, D. A. 1997. Principles and Procedures of Statistics: A Biometrical Approach, 3rd ed. McGraw-Hill, New York.

23. Tarr, S. A. J. 1962. Root and stalk diseases: Red stalk rot, Colletotrichum rot, anthracnose, and red leaf spot. Pages 58-73 in: Diseases of Sorghum, Sudan Grass and Brown Corn. Commonwealth Mycological Institute, Kew, Surrey, England.

24. Thakur, R. P., Mathur, K., Rao, V. P., Chandra, S., Sivaramkrishnan, S., Kannan, S., Hiremath, R. V., Tailor, H. C., Kushwaha, U. S., Dwivedi, R. R., and Indira, S. 1998. Pathogenic and genetic characterization of six Indian populations of Colletotrichum sublineolum, the causal agent of sorghum anthracnose. Ind. Phytopathol. 51:338-348.

25. Thomas, M. D. 1992. Sorghum diseases in western Africa. Pages 25-29 in: Sorghum and Millets Diseases: A Second World Review. W.
A. J. de Milliano, R. A. Frederiksen, and G D. Bengston, eds. International Crops Re search Institute for the Semi-Arid Tropics, Patancheru 502 324, A. P., India.

26. Thomas, M. D., Sissoko, I., and Sacko, M. 1996. Development of leaf anthracnose and its effect on yield and grain weight of sorghum in West Africa. Plant Dis. 80:151-153.

27. Ward, J. H. 1963. Hierarchical grouping to optimize an objective function. J. Am. Stat. Assoc. 58:236-244.

28. Watson, S. H., DeLacy, I. H., Podlich, D. W and Basford, K. E. 1996. GEBEI: An analysis package using agglomerative hierarchical classificatory and SVD ordination procedures for genotype $\times$ environment data. Research Report \#57, Department of Mathematics, The University of Queensland, Brisbane, Australia. Published on-line

29. Williams, W. T. 1976. Hierarchical agglomerative strategies. Pages 84-90 in: Pattern Analysis in Agricultural Science. W. T. Williams, ed. Elsevier Scientific Publishing, Amsterdam, The Netherlands.

30. Wishart, D. 1969. An algorithm for hierarchical classifications. Biometrics 25:165-170. 